\title{
CFD Analysis of Different Aeration Ducts on Temperature and Airflow in Stored Maize
}

\author{
Marcos E. V. Araujo ${ }^{1}$, Eloiny G. Barbosa ${ }^{1}$, Marcio A. Martins ${ }^{1}$, Paulo C. Corrêa ${ }^{1}$, Elisa G. Barbosa ${ }^{2}$, \\ Rodrigo S. L. Araújo ${ }^{3} \&$ Felipe A. Gomes ${ }^{3}$ \\ ${ }^{1}$ Federal University of Viçosa, Department of Agricultural Engineering,Viçosa, Minas Gerais, Brazil \\ ${ }^{2}$ State University of Goiás, Department of Chemistry, Anápolis, Goiás, Brazil \\ ${ }^{3}$ State University of Goiás, Department of Agricultural Engineering, Anápolis, Goiás, Brazil \\ Correspondence: Marcos E. V. Araujo, Federal University of Viçosa, Department of Agricultural \\ Engineering,Viçosa, Minas Gerais, Brazil. Tel: 55-629-9365-5562. E-mail: marcos.rav@hotmail.com
}

Received: September 20, 2018

Accepted: November 1, 2018

Online Published: January 15, 2019

doi:10.5539/jas.v11n2p301

URL: https://doi.org/10.5539/jas.v11n2p301

The research is financed by National Council for Scientific and Technological Development (CNPq) and by Coordination for the Improvement of Higher Education Personnel (CAPES).

\begin{abstract}
The conditions of temperature and airflow distribution in the mass of stored grains are highly influenced by the configuration of the aeration ducts. However, silos are large structures, and the physical experiments on them become expensive and slow. Thus, this study aimed model and evaluate the temperature and airflow distribution in a maize mass, stored in a metal silo with different geometries of aeration ducts, using CFD (computational fluid dynamic). CFD was used to model and evaluate aeration ducts of square, ring, double bar and single bar shape. The proposed model was validated from experimental data. The airflow distribution and temperature in the grain mass were analyzed at different points. The ducts of a square and a ring shape showed better distributions of airflow in the grain mass, with averages of $0.00236 \mathrm{~m} \mathrm{~s}^{-1}$ and $0.00275 \mathrm{~m} \mathrm{~s}^{-1}$, respectively. The square shape aeration duct, presented better temperature values in the middle layer of the grain mass during aeration, with average $25.09^{\circ} \mathrm{C}$. CFD can be used in decision making for the best design of a silo, saving financial resources and time, as long as the parameters used in the simulation are reliable and represent the reality.
\end{abstract}

Keywords: computational fluids dynamic, Navier-Stokes, simulation, stored grains

\section{Introduction}

The successive increase in world grain production, and continuous demand for product throughout the year, make storage an indispensable operation (Oladunde et al., 2016; Lopes et al., 2015). The correct storage preserves the quality of products and guarantees their longevity until the consumption (Hendges et al., 2017). Bulk grain storage is commonly performed in elevated cylindrical silos equipped with aeration ducts (Khatchatourian \& Oliveira, 2006). The aeration ducts can have different shapes, being the circular duct the most used (Khatchatourian et al., 2017).

The temperature conditions and the airflow distribution in grain mass, depend primarily of aeration ducts shape, ambient temperature, grain temperature in neighboring layers and the aeration period (Navarro \& Noyes, 2001). Thus, the way airflow and temperature are distributed in the grain mass, will result in the homogeneity of the aerated product (Amanlou \& Zomorodian, 2010). According to Lopes et al. (2008), the positioning and the format of the aeration ducts, can result in an irregularity of temperature inside the silo, both along its longitudinal axis and its cross section.

The use of Computational Fluid Dynamics (CFD) to predict phenomena within silos has been widespread in recent decades. Studies conducted by Tascón et al. (2011), Garcia et al. (2015), and Larsson et al. (2012), demonstrate the potential use of CFD to predict some phenomena, such as particles segregation in grain mass, 
and temperature patterns during storage. In addition, Devilla et al. (2005) were successful in validating the airflow distribution model in vertical silos with ring-shaped aeration ducts using CFD.

Silos are large structures, and the physical experiments on them become expensive and slow. Although CFD cannot completely replace physical experiences, it can significantly reduce the cost and time required for such studies. Although this tool has been used in studies involving silos, data about influence of the aeration duct shape are not found in the literature.

Thus, this study aimed model and evaluate the temperature and airflow distribution in a maize mass, stored in a metal silo with different geometries of aeration ducts, using CFD.

\section{Material and Methods}

\subsection{Flow Domain and Aeration Ducts Shapes}

The runoff domain used in this study can be seen in Figure 1. The domain consists in a maize mass (13\% w.b.) of $1.6 \mathrm{~m}$ height, in a metallic silo with emissivity and absorbance of 0.28 and 0.5 respectively (INCROPERA \& DE WITT, 1996). The silo has a radius of $1.8 \mathrm{~m}$, and an air outlet of $0.65 \mathrm{~m}$ diameter and $0.075 \mathrm{~m}$ height.

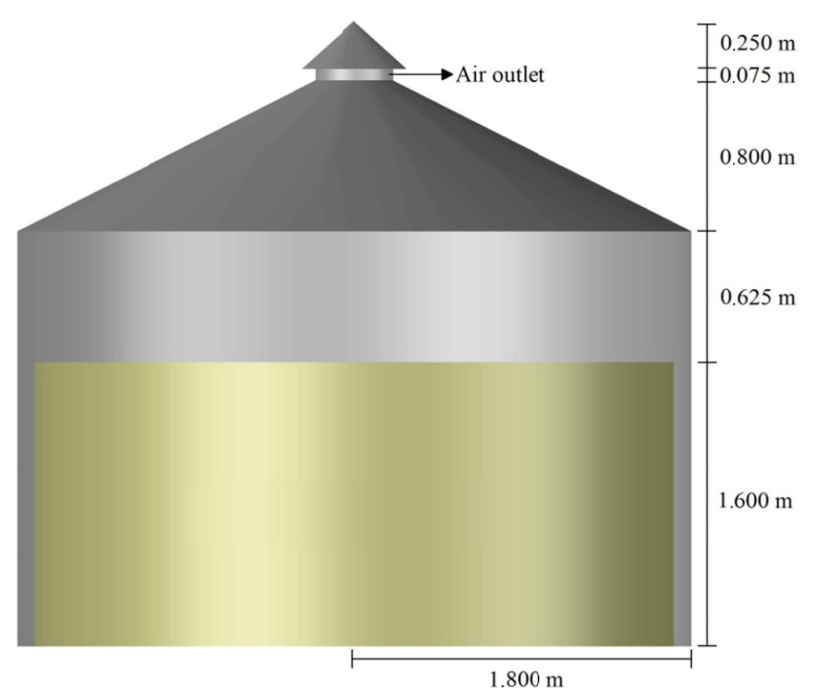

Figure 1. Flow domain used in CFD simulation

We considered that for a given moment of time, half silo was submitted to a condition of constant heat flux (694.4 $\mathrm{W} \mathrm{m}^{-2}$ ) equivalent to the average incident radiation for Viçosa - MG, Brazil (INMET, 2018). The airflow was introduced into the bottom of silo by means of openings simulating perforated aeration ducts. The ducts were dimensioned so that all had the same perforated area $\left(1.5 \mathrm{~m}^{2}\right)$, being designed with different shapes: ring (Figure 2A), double bar (Figure 2B), single bar (Figure 2C), and square (Figure 2D). 

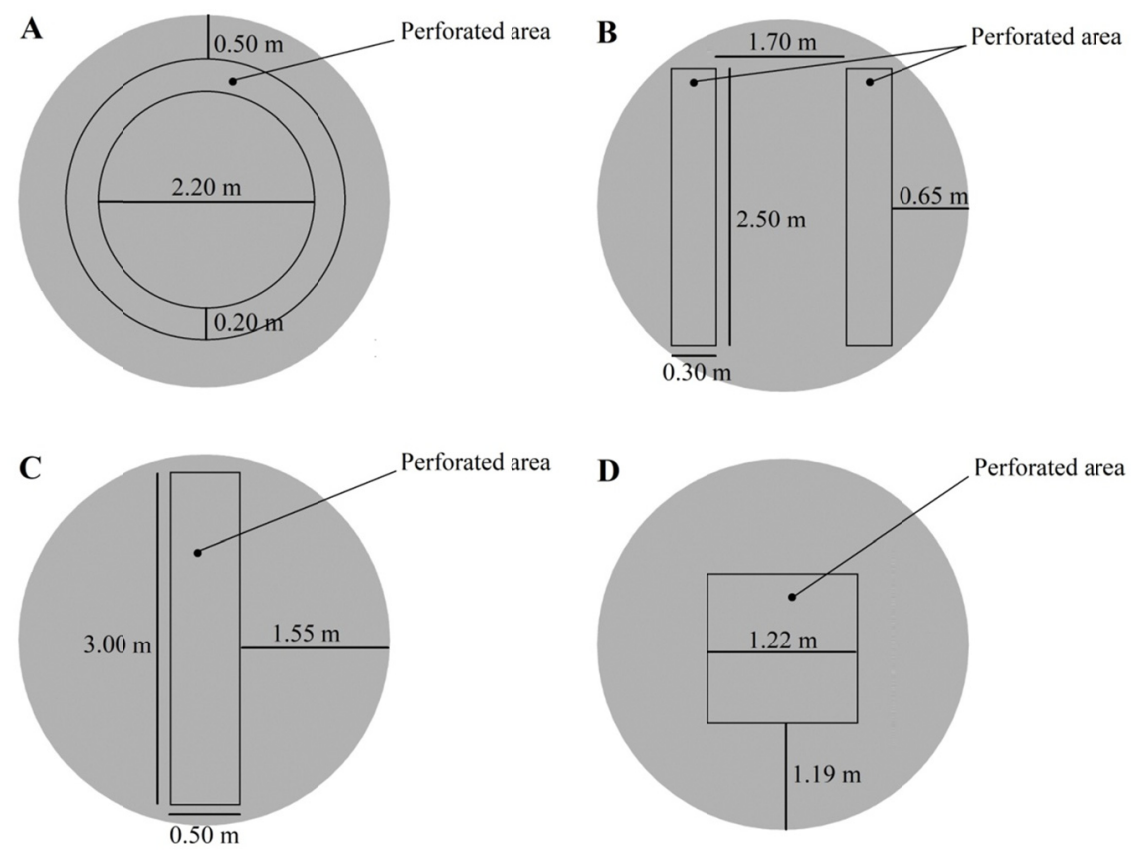

Figure 2. Aeration ducts shapes: ring (A), double bar (B), single bar (C) and square (D)

\subsection{Assumptions Used on Simulation}

This CFD code is based on the following assumptions:

- Permanent flow;

- The flow is two-dimensional, stable, fully developed and turbulent;

- The maize mass is treated as porous medium;

- Anisotropic medium;

- The silo's walls have negligible mass when compared with maize mass, and as such the losses by conduction can be neglected;

- Friction on walls is despicable.

\subsection{Governing Equations}

The governing equations of the constant flow of air through the aeration ducts are obtained by applying the laws of mass conservation (Equation 1) and momentum (Navier-Stokes), in which the natural convection inside the silo is modeled by the Boussinesq approximation (Equation 2) and energy (Equation 3).

$$
\begin{gathered}
\frac{\partial}{\partial x_{j}}\left(u_{j}\right)=0 \\
\frac{\partial u_{i}}{\partial t}+u_{j} \frac{\partial u_{i}}{\partial x_{j}}=-\frac{1}{\rho} \frac{\partial p}{\partial x_{i}}+v \frac{\partial^{2} u_{i}}{\partial x_{j} x_{j}}+\beta \rho\left(T-T_{r e f}\right) g_{i} \\
\frac{\partial\left(u_{j} T\right)}{\partial x_{j}}=\alpha \frac{\partial}{\partial x_{j}}\left(\frac{\partial T}{\partial x_{j}}\right)+\frac{\mu_{t}}{\rho \sigma_{t}} \frac{\partial}{\partial x_{j}}\left(\frac{\partial T}{\partial x_{j}}\right)
\end{gathered}
$$

\subsection{Support Equations}

The Reynolds number was calculated for the four simulated ducts, presenting for all cases values higher than 2000 , characterizing the flow as turbulent inside the silo. Among the turbulent models, the $\mathrm{k}-\varepsilon$ model remains an industrial standard, and for this reason, it was used in this modeling. The standard $k-\varepsilon$ model is a semi-empirical model based on the transport equations for the turbulent kinetic energy (k) (Equation 4) and its dissipation rate (ع) (Equation 5), as presented by Amanlou \& Zomorodian (2010).

$$
\frac{\partial}{\partial \mathrm{t}}(\rho \mathrm{k})+\frac{\partial}{\partial \mathrm{x}_{\mathrm{i}}}\left(\rho \mathrm{ku}_{\mathrm{i}}\right)=\frac{\partial}{\partial \mathrm{x}_{\mathrm{j}}}\left[\left(\mu+\frac{\mu_{\mathrm{t}}}{\sigma_{\mathrm{k}}}\right) \frac{\partial \mathrm{k}}{\partial \mathrm{x}_{\mathrm{j}}}\right]+\mathrm{G}_{\mathrm{k}}+\mathrm{G}_{\mathrm{b}}-\rho \varepsilon-\mathrm{Y}_{\mathrm{M}}+\mathrm{S}_{\mathrm{k}}
$$




$$
\frac{\partial}{\partial \mathrm{t}}(\rho \varepsilon)+\frac{\partial}{\partial \mathrm{x}_{\mathrm{i}}}\left(\rho \varepsilon \mathrm{u}_{\mathrm{i}}\right)=\frac{\partial}{\partial \mathrm{x}_{\mathrm{j}}}\left[\left(\mu+\frac{\mu_{\mathrm{t}}}{\sigma_{\varepsilon}}\right) \frac{\partial \varepsilon}{\partial \mathrm{x}_{\mathrm{j}}}\right]+\mathrm{G}_{1 \varepsilon} \frac{\varepsilon}{\mathrm{k}}\left(\mathrm{G}_{\mathrm{k}}+\mathrm{C}_{3 \varepsilon} \mathrm{G}_{\mathrm{b}}\right)-\mathrm{C}_{2 \varepsilon} \rho \frac{\varepsilon^{2}}{\mathrm{k}}+\mathrm{S}_{\varepsilon}
$$

The heat flux absorbed by the silo was calculated by performing the energy balance in the walls, relating the gains by absorbance and losses by radiation and convection (Equation 6).

$$
\mathrm{q}=\mathrm{G} \alpha-\mathrm{h}\left(\mathrm{T}_{\text {sup }}-\mathrm{T}_{\infty}\right)-\varepsilon \sigma \mathrm{T}_{\text {sup }}^{4}
$$

Where, q: heat flux absorbed, $\mathrm{W} \mathrm{m}^{-2} ; \mathrm{G}$ : incident radiation flux, $\mathrm{W} \mathrm{m}^{-2} ; \alpha$ : material Absorbency; $\mathrm{h}$ : convective heat transfer coefficient, $\mathrm{W} \mathrm{m}^{-2} \mathrm{~K}^{-1} ; \mathrm{T}_{\text {sup }}$ : surface temperature, $\mathrm{K} ; \mathrm{T}_{\infty}$ : neighborhood temperature; $\varepsilon$ : material emissivity; $\sigma$ : Stefan-Boltzmann constant, $5.6710^{-8} \mathrm{~W} \mathrm{~m}^{-2} \mathrm{~K}^{-4}$.

\subsection{Initial and Boundary Conditions}

In this study, the following boundary conditions were used:

- Inlet: $\mathrm{u}=\mathrm{w}=0 \mathrm{~m} \mathrm{~s}^{-1}, \mathrm{v}=0.0157 \mathrm{~m} \mathrm{~s}^{-1}, \mathrm{~T}=23^{\circ} \mathrm{C}(296.16 \mathrm{~K})$, turbulence intensity $=5 \%$.

- Opening: $\mathrm{P}=0 \mathrm{~Pa}$, turbulence intensity $=5 \%, \mathrm{~T}=23^{\circ} \mathrm{C}(296.16 \mathrm{~K})$.

- Wall: $\mathrm{u}=\mathrm{v}=0$ (no slip), $\mathrm{h}=5 \mathrm{~W} \mathrm{~m}^{-2} \mathrm{~K}^{-1}, \mathrm{~T}=\mathrm{T}_{\text {sup }}$, heat flux $=\mathrm{q}$ (Equation 6).

Where, $\mathrm{u}, \mathrm{v}, \mathrm{w}$ : components of velocity in the directions $\mathrm{x}, \mathrm{y}$ and $\mathrm{z}$, respectively; $\mathrm{T}$ : temperature; P: relative pressure; h: convective heat transfer coefficient.

The porous medium (maize mass) was implemented using the models and empirical parameters found by Devilla et al. $(2004,2005)$, in its experimental analysis of the temperature and airflow distribution in a maize mass stored in aerated silos, for purposes of validation of the proposed model.

\subsection{Numerical Methodology}

The governing and support equations were resolved using a CFD code ANSYS CFX version 14.5 based in finite volume on an HP ProLiant ML150G6 computer with Intel (R) Xeon (R) processor, $2.00 \mathrm{GHz}$ CPU E5504, and RAM 12.0 GB, belonging to the biofuels laboratory, of the Federal University of Viçosa, Brazil.

The meshes used for implementation were composed of 104372, 112550, 103651 and 102977 nodes and 544777, 589229,540904 and 537634 elements for silos with aeration ducts shaped as double bar, ring, single bar and square respectively, using local refinement in critical runoff regions. The mesh independence tests were performed by successive refinement of the mesh until the variables temperature and velocity at a given point presented variations below $0.01{ }^{\circ} \mathrm{C}$ and $10^{-5} \mathrm{~m} \mathrm{~s}^{-1}$, respectively.

To perform the simulation, high-resolution advection schemes and numerical models of first order turbulence were used. The minimum and maximum number of interactions were defined in 1 and 1000 respectively, using a physical time scale of 1 second, and convergence criterion based on Mean Square Error (MSE) less than $10^{-4}$.

\subsection{Validation}

For the validation of the proposed model, the experimental data obtained by Devilla et al. (2004, 2005). The authors used a system consisting of a cylindrical metal silo of $3.6 \mathrm{~m}$ diameter and $2.2 \mathrm{~m}$ height, loaded with maize (13\% w.b.) up to $1.6 \mathrm{~m}$ in height and a ring-shaped aeration duct with perforated area of $1.5 \mathrm{~m}^{2}$. In the study, the authors performed several tests evaluating the temperature using " $\mathrm{T}$ " thermocouples and air velocities using a rotating blade anemometer at various points on the surface of maize mass from the inlet velocity of $0.0157 \mathrm{~m} \mathrm{~s}^{-1}$. For the validation, the velocities were evaluated at 20 points located on the surface of the silo, and temperatures were evaluated at 20 points along the silo diameter located at the center of maize mass, according to the experimental tests performed by the authors.

\section{Results and Discussion}

In the simulations, the average air velocity found on the surface of the grain mass was $0.0023 \mathrm{~m} \mathrm{~s}^{-1}$, with values ranging from $0.0020 \mathrm{~m} \mathrm{~s}^{-1}$ to $0.0026 \mathrm{~m} \mathrm{~s}^{-1}$. The values found corroborate with those obtained experimentally by Devilla et al. (2004), who, when analyzing the airflow behavior on the surface of the stored maize, found a mean surface velocity value of $0.0022 \mathrm{~m} \mathrm{~s}^{-1}$, ranging from $0.0020 \mathrm{~m} \mathrm{~s}^{-1}$ to $0.0024 \mathrm{~m} \mathrm{~s}^{-1}$. There is a similarity of velocity distribution between the proposed model and the data obtained experimentally (Figure 3). Thus, the proposed model can represents physically and numerically the prediction of velocity distribution in a silo with aeration system. 


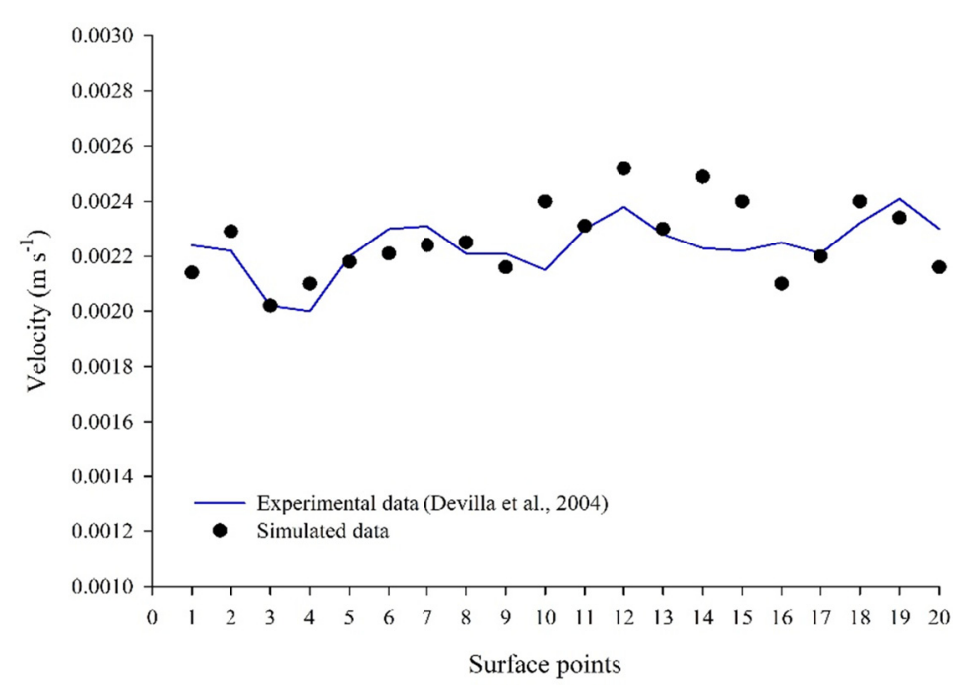

Figure 3. Simulated data vs experimental data, for the silo with ring-shaped duct

The temperature values were obtained for the 20 points in the center of the maize mass. Figure 4 shows the values found for the silo with ring-shaped aeration duct. Note that there is an increase in the temperature of the grain mass in the regions near the wall. This can be explained by the geometric shape and positioning of the circular aeration duct, which creates higher temperature zones on the walls (Lopes et al., 2008).

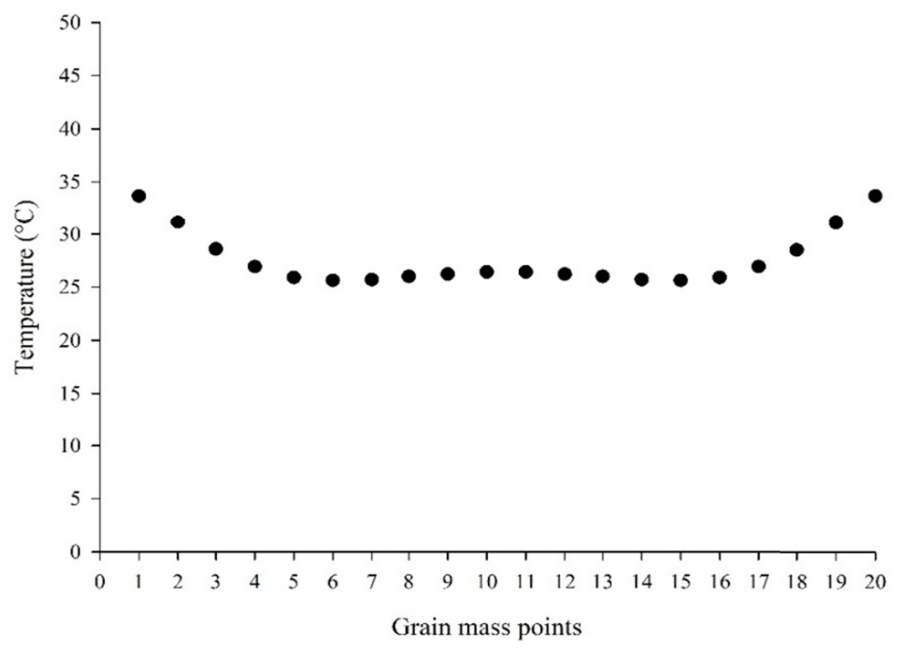

Figure 4. Simulated temperature results in the center of maize mass, for the silo with ring-shaped duct

It is observed that the average maize mass temperature was $27.6^{\circ} \mathrm{C}$, ranging from $25.6{ }^{\circ} \mathrm{C}$ to $33.7^{\circ} \mathrm{C}$. The values obtained in the simulation match those observed experimentally by Devilla et al. (2005), who found temperature values between $22.0^{\circ} \mathrm{C}$ and $33.8{ }^{\circ} \mathrm{C}$, and average of $27.0^{\circ} \mathrm{C}$. Thus, the model proposed in this study represents physically and numerically the prediction of temperatures in maize mass stored in silo with aeration system. The temperature variation in stored products is frequently observed, and is due to the non-uniformity airflow in the product.

After validation, it was possible to study the distribution of airflow and temperatures in the center of maize mass for the four aeration ducts evaluated. It is observed in Figure 5, the simulation results for temperature in the center maize mass for the different geometries. The aeration ducts in a ring and double bar shape, promote similar bulk grain temperatures, causing a rise in temperature in the central part and near the walls of the silo. On the other hand, ducts with single and square bar shape promote higher temperatures only in the walls of the silo, 
with the lowest temperatures recorded in the central part of grain mass. These results are a consequence of the position of the air ducts and their shapes.

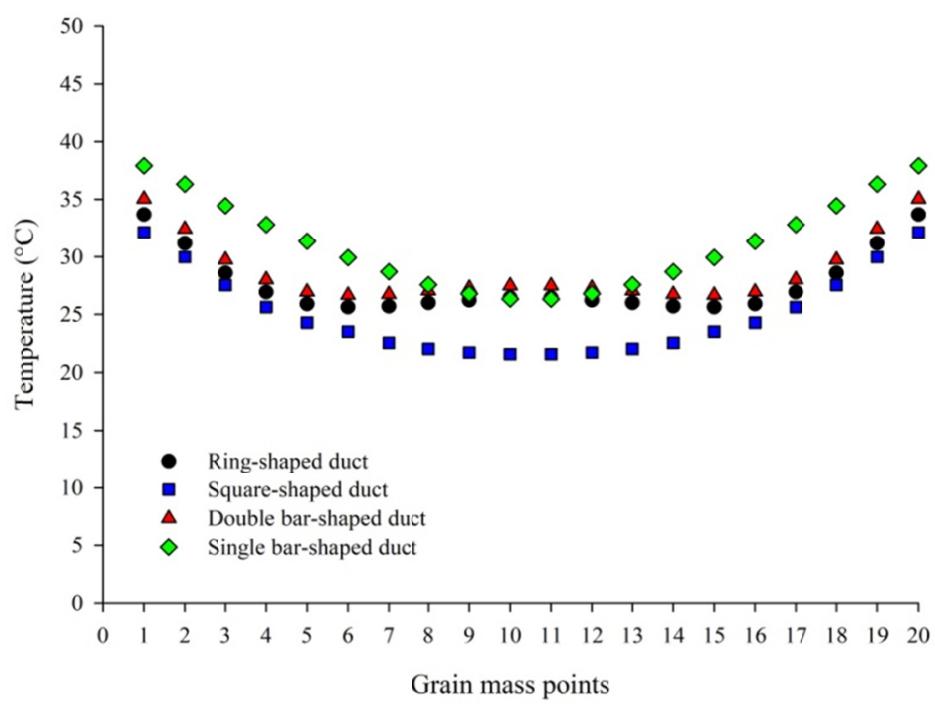

Figure 5. Simulated temperature results in the center of grain mass for different aeration ducts

The observed averages for single bar, ring, double bar and square ducts, were $31.21{ }^{\circ} \mathrm{C}, 27.63{ }^{\circ} \mathrm{C}, 28.73{ }^{\circ} \mathrm{C}$ and $25.09{ }^{\circ} \mathrm{C}$, respectively. The values found in the simulation are within the usual range found inside the grain mass during aeration. Carrera-Rodriguez et al. (2011) numerically evaluated the effect of ambient temperature on grain storage by finding temperature values in the grain mass between $25{ }^{\circ} \mathrm{C}$ and $30^{\circ} \mathrm{C}$. This result proves that CFD can accurately predict temperature phenomena within silos.

The single bar duct promoted higher temperatures in the grain mass in almost all points evaluated, and for this reason, it is not recommended for aeration systems. The square duct promoted better uniformity of temperature in the grain mass, presenting considerably lower temperatures in the center when compared to the commonly used duct (ring). Thus, the duct of square shape presented the best results and was the most suitable for silos with aeration system. It is emphasized that the aeration operation seeks the cooling of the grains so that there is no significant losses due to hygroscopicity of the product. All agricultural products have the ability to yield or absorb water, constantly converging to a balance between their water content and ambient air conditions (Oliveira et al., 2015).

The airflow distributions in the central layer of the grain mass can be seen in Figure 6. The behavior of the curves of the airflow distribution are opposite to those found for the temperatures. This result was expected, as increased airflow promotes greater grain mass cooling. The double bar and single bar ducts, presented flows with low speeds, when compared to the other geometries, presenting averages of $0.00184 \mathrm{~m} \mathrm{~s}^{-1}$ and $0.00195 \mathrm{~m} \mathrm{~s}^{-1}$, respectively. The square duct had low values of velocity close to the wall; however, it presented high values in the center of the silo, where the points of greater temperature in the mass of stored grains are usually found. The mean velocity in the square-shaped duct was $0.00236 \mathrm{~m} \mathrm{~s}^{-1}$, with values ranging from $0.00132 \mathrm{~m} \mathrm{~s}^{-1}$ to 0.00329 $\mathrm{m} \mathrm{s}^{-1}$. The ring-shaped duct presents good distribution of the flow near the walls, however the central region of the silo presents low values of velocity explaining the increase of temperature in this region, evidenced previously (Figure 5). Although the ring-shaped duct presents an average of $0.00275 \mathrm{~m} \mathrm{~s}^{-1}$, superior to the other ducts, the square-shaped duct presented better values of temperature and distribution of the airflow, being recommended for aeration operations. 


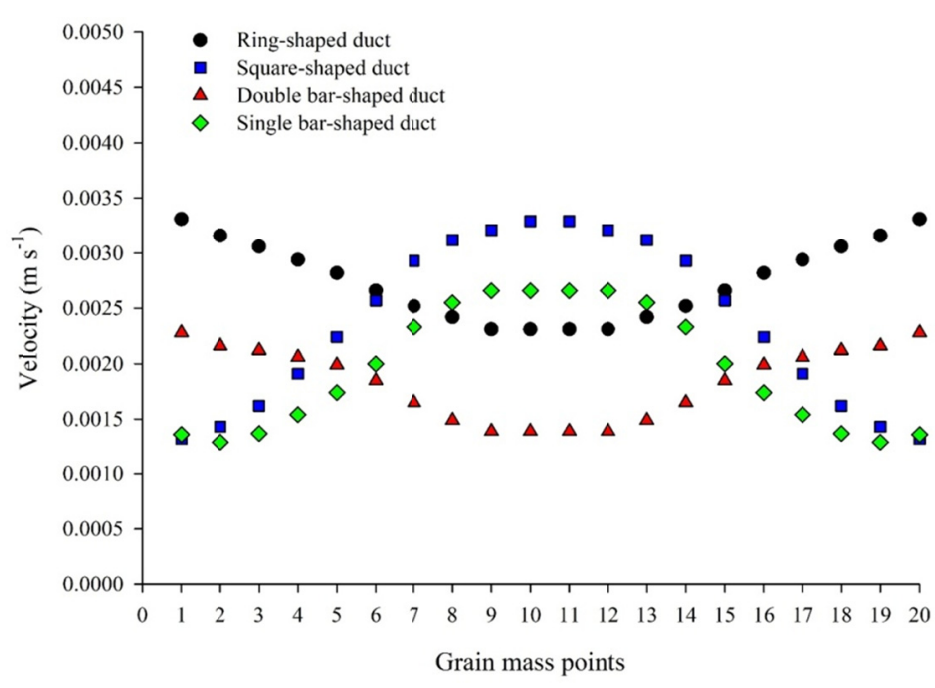

Figure 6. Air velocity $\left(\mathrm{m} \mathrm{s}^{-1}\right)$ of central region of the grain mass

The non-uniform distribution of airflow is caused within the silo by the grain mass, and by its variable porosity. When formulating the variable porosity, the porosity at the centroid of a finite element was calculated by interpolation as presented by Lawrence and Maier (2011). The non-uniform flow distribution in silos was also observed by Bartosik and Maier (2006) analyzing experimentally and numerically the air flow distribution in different silos with different grain mass configurations.

CFD has been shown to be a viable tool for analyzing the airflow and temperature of the grain mass for the different aeration ducts. Zhang et al. (2017) when evaluating the difference of the aeration duct grouping in horizontal silos, also concluded that this tool is powerful, and is able to predict the phenomena of distribution of airflow and temperature in the mass of stored grains. The use of CFD was also accurate in simulations of other parameters and phenomena in silos by several authors (Klippel et al., 2014; Rani et al., 2015; Tascón \& Aguardo, 2015; Isa et al., 2016; Lee et al., 2016; Tascón, 2017). This demonstrates that CFD can be used in decision making on the best design of a silo, saving financial resources and time. However, caution should be exercised when extrapolating these results to different cases, since results obtained in the simulations are very dependent on the initial scenario considered.

\section{Conclusions}

The use of CFD to predict the distribution of temperature and airflow in silos with aeration system was satisfactory, presenting values close to the experimental ones. The distribution of air in the middle layer of the grain mass is highly related to the aeration duct shape.

The square and ring ducts presented better distributions of airflow in maize mass, with averages of $0.00236 \mathrm{~m} \mathrm{~s}^{-1}$ and $0.00275 \mathrm{~m} \mathrm{~s}^{-1}$, respectively. The square-shaped aeration duct presented better temperature values in the central layer of the grain mass during aeration, presenting an average of $25.09^{\circ} \mathrm{C}$.

CFD can be used in decision making for the best design of a silo, saving financial resources and time, as long as the parameters used in the simulation are reliable and represent the reality.

\section{References}

Amanlou, Y., \& Zomorodian, A. (2010). Applying CFD for designing a new fruit cabinet dryer. Journal of Food Engineering, 101, 8-15. https://doi.org/10.1016/j.jfoodeng.2010.06.001

Bartosik, R. E., \& Maier, D. E. (2006). Effect of airflow distribution on the performance of NA/LT in-bin drying of corn. Transactions of ASABE, 49, 1095-1104. https://doi.org/10.13031/2013.21715

Carrera-Rodrigues, M., Martínez-Gonzáles, G., Navarrete-Bolaños, J., Botello-Alvarez, E., Rico-Martinez, R., \& Jiménez-Ilhas, H. (2011). Transient numerical study of the effect of ambient temperature on 2-D cereal grain storage in cylindrical silos. Journal of Stored Products Research, 47, 106-122. https://doi.org/10.101 6/j.jspr.2011.01.006 
Devilla, I. A., Couto, S. M., \& Queiroz, D. M. (2005). Distribuição do fluxo de ar em silos com sistema de aeração: Análise por elementos finitos. Revista Brasileira de Engenharia Agrícola e Ambiental, 9, 256-262. https://doi.org/10.1590/S1415-43662005000200017

Devilla, I. A., Couto, S. M., Zolnier, S., \& Silva, J. S. (2004). Variação da temperatura e umidade de grãos de milho armazenados em silos com aeração. Revista Brasileira de Engenharia Agrícola e Ambiental, 8 , 284-291. https://doi.org/10.1590/S1415-43662004000200018

Garcia, M. C., Feise, H. J., Strege, S., \& Kwade, A. (2015). Segregation in heaps and silos: Comparison between experimente, simulation and continuum model. Powder Technology, 293, 26-36. https://doi.org/10.1016/ j.powtec.2015.09.036

Hendges, C., Luzzi, D., Walcker, R., Finger, J. I., Carmelo, D. B., Lubian, C., ... Kaefer, J. E. (2017). Physiological Potential of Bean Seeds under Different Storage Temperatures. Journal of Agricultural Science, 9, 82-87. https://doi.org/10.5539/jas.v9n12p82

Incropera, F. P., \& De Witt, D. P. (1996). Fundamentals of heat and mass transfer. New York, John Wiley \& Sons.

INMET (Instituto Nacional de Meteorologia). (2017). Estação Meteorológica de Observação de Superfície Automática. Retrieved from http://www.inmet.gov.br/portal/index.php?r=estacoes/estacoesAutomaticas

Isa, Z. M., Farrell, T. W., Fulford, G. R., \& Kelson, N. A. (2016). Mathematical modelling and numerical simulation of phosphine flow during grain fumigation in leaky cylindrical silos. Journal of Stored Products Research, 67, 28-40. https://doi.org/10.1016/j.jspr.2016.01.002

Khatchatourian, O. A., \& Oliveira, F. A. (2006). Mathematical Modelling of Airflow and Thermal State in Large Aerated Grain Storage. Biosystems Engineering, 95, 159-169. https://doi.org/10.1016/j.biosystemseng.200 6.05 .009

Khatchatourian, O. A., Binelo, M. O., Neutzling, B., \& Faoro, V. (2017). Models to predict the termal state of rice stored in aerated vertical silos. Biosystems Engineering, 161, 14-23. https://doi.org/10.1016/j.biosystem seng.2017.06.013

Klippel, A., Schmidt, M., Muecke, O., \& Krause, U. (2014). Dust concentration measurements during filling of a silo and CFD modeling of filling processes regarding exceeding the lower explosion limit. Journal of Loss Prevention in the Process Industries, 29, 122-137. https://doi.org/10.1016/j.jlp.2014.02.006

Larsson, S. H., Lestander, T. A., Crompton, D., \& Melin, S. Sokhansanj, S. (2012). Temperature patterns in large scale wood pellet silo storage. Applied Energy, 92, 322-327. https://doi.org/10.1016/j.apenergy.2011.11.012

Lawrence, J., \& Maier, D. E. (2011). Three-dimensional airflow distribution in a maize silo with peaked, levelled and cored grain mass configurations. Biosystems Engineering, 110, 321-329. https://doi.org/10.1016/j.bios ystemseng.2011.09.005

Lee, D., Cantou, N., Park, J., \& Chung, S. (2016). An assessment of temperature history on concrete silo dry storage system for CANDU spent fuel. Annals of Nuclear Energy, 94, 263-271. https://doi.org/10.1016/ j.anucene.2016.03.007

Lopes, D. C., Martins, J. H., Filho, A. F. L., Melo, E. C., Monteiro, P. M. B., \& Queiroz, D. M. (2008). Aeration strategy for controlling grain storage based on simulation and on real data acquisition. Computers and Electronics in Agriculture, 63, 140-146. https://doi.org/10.1016/j.compag.2008.02.002

Lopes, D. C., Steidle Neto, A. J., \& Vasco Junior R. (2015). Comparison of equilibrium models for grain aeration. Journal of Stored Products Research, 60, 11-18, 2015. https://doi.org/10.1016/j.jspr.2014.11.001

Navarro, S., \& Noyes, R. T. (2001). The mechanics and physics of modern grain aeration management. Florida, USA: CRC Press LLC. https://doi.org/10.1201/9781420040333

Olatunde, G., Atungulu, G. G., \& Sadaka, S. (2016). CFD modeling of airflow distribution in rice bin storage system with different grain mass configurations. Biosystems Engineering, 151, 286-297. https://doi.org/ 10.1016/j.biosystemseng.2016.09.007

Oliveira, G. H. H., Corrêa, P. C., Oliveira, A. P. L. R., Reis, R. C., \& Devilla, I. A. (2015). Application of GAB Model for Water Desorption Isotherms and Thermodynamic Analysis of Sugar Beet Seeds. Journal of Food Process Engineering, 40,1-8. https://doi.org/10.1111/jfpe.12278 
Rani, S. I., Aziz, B. A., \& Gimbun, J. (2015). Analysis of dust distribution in silo during axial filling using computational fluid dynamics: Assessment on dust explosion likelihood. Process Safety and Environmental Protection, 96, 14-21. https://doi.org/10.1016/j.psep.2015.04.003

Tascón, A. (2017). Design of silos for dust explosions: Determination of vent area sizes and explosion pressures. Engineering Structures, 134, 1-10. https://doi.org/10.1016/j.engstruct.2016.12.016

Tascón, A., \& Aguado, P. J. (2015). CFD simulations to study parameters affecting dust explosion venting in silos. Powder Technology, 272, 134-142. https://doi.org/10.1016/j.powtec.2014.11.031

Tascón, A. Ruiz, A., \& Aguado, P. J. (2011). Dust explosions in vented silos: Simulations and comparisons with current standards. Powder Technology, 208, 717-724. https://doi.org/10.1016/j.powtec.2011.01.015

Zhang, H., Li, X., Wang, Y., Yao, J., Kang, Y., \& Wang, Y. (2017). Evaluation and analysis of internal flow field uniformity in grain stack based on multi zone model of porous media. Procedia Engineering, 205, 2164-2170. https://doi.org/10.1016/j.proeng.2017.10.036

\section{Copyrights}

Copyright for this article is retained by the author(s), with first publication rights granted to the journal.

This is an open-access article distributed under the terms and conditions of the Creative Commons Attribution license (http://creativecommons.org/licenses/by/4.0/). 